\title{
List context effects on masked phonological priming in the lexical decision task
}

\author{
LUDOVIC FERRAND \\ C.N.R.S. and Université René Descartes, Paris, France \\ and \\ JONATHAN GRAINGER \\ C.N.R.S. and Université de Provence, Aix-en-Provence, France
}

\begin{abstract}
A lexical decision experiment tested the effects of briefly presented masked primes that were homophones or pseudohomophones of target words. Different types of nonword foil (pseudohomophones, orthographically regular nonwords, orthographically irregular nonwords) were mixed with the word targets. Pseudohomophone priming effects were independent of nonword foil variations, whereas homophone priming effects varied from being facilitatory in the presence of orthographically regular nonwords, inhibitory in the presence of pseudohomophones, and null in the presence of irregular nonwords. This dissociation in the way nonword foil variations influence masked pseudohomophone and homophone priming effects in the lexical decision task is discussed within the framework of a bimodal extension of the multiple readout model of visual word recognition (Grainger \& Jacobs, 1996).
\end{abstract}

There is currently a large amount of evidence showing that phonological information influences performance in various paradigms used to investigate printed-word perception. Perhaps the clearest evidence for early constraints of phonology in visual word recognition comes from priming studies using visual masking procedures and very brief prime-presentation durations (e.g., Ferrand \& Grainger, 1992; Humphreys, Evett, \& Taylor, 1982; Lukatela \& Turvey, 1994; Perfetti, Bell, \& Delaney, 1988). One important question concerning phonological coding in visual word recognition is whether or not it is optional (i.e., under strategic control). To address the question of strategic control in visual word recognition, experimental psychologists often manipulate the degree to which nonword stimuli resemble real words (nonword lexicality) in the lexical decision task (e.g., Stone \& Van Orden, 1993).

With respect to masked pseudohomophone priming effects in the lexical decision task, Ferrand and Grainger (1992) demonstrated that adding pseudohomophones to the nonword targets did not influence the priming effect obtained with word targets. On the other hand, Grainger and Ferrand (1994) demonstrated that phonological priming effects obtained with homophone primes in the lexical decision task are sensitive to the presence of pseudohomophones among the nonword targets. This study examined the effects of orthographically related high-frequency primes that were homophones of low-frequency target words (e.g., real-REEL). Facilitatory priming effects were

The authors thank Randi Martin, Annette de Groot, and Johannes Ziegler for helpful comments on this work. Correspondence should be addressed to L. Ferrand, Laboratoire de Psychologie Experimentale, CNRS, 28 rue Serpente, 75006 Paris, France, or to J. Grainger, Université de Provence, CREPCO, 29 av. R. Schuman, 13621 Aix-en-Provence, France (e-mail: ferrandl@idf.ext.jussieu.fr, or grainger@aixup.univ-aix.fr). obtained relative to unrelated primes in the absence of pseudohomophone foils, whereas inhibitory effects were obtained in the presence of pseudohomophone foils. ${ }^{1}$ Thus, although the effects of pseudohomophone primes appear to reflect automatic processing in visual word recognition, homophone priming appears subject to strategic control. This is a rather uncomfortable conclusion in view of the fact that, in the masked priming paradigm, participants are generally unable to indicate whether the prime was a pseudohomophone or a homophone of the target. Clearly, these results pose a dilemma with respect to the automatic or strategic nature of phonological coding in visual word recognition.

The present experiment provides a systematic investigation of list composition effects on pseudohomophone and homophone priming. In the Grainger and Ferrand (1994) study, all the targets were homophones; in the Ferrand and Grainger (1992) study, only some of the targets were homophones. Thus, the differential sensitivity of homophone and pseudohomophone priming to the presence of pseudohomophone foils might have arisen because strategic control of phonological coding only occurs with a high percentage of homophones among the word targets. Alternatively, the different influence of nonword context on pseudohomophone and homophone priming effects can be accommodated within the theoretical framework to be described briefly below.

\section{A THEORETICAL FRAMEWORK FOR INTERPRETING LIST COMPOSITION EFFECTS IN LEXICAL DECISION}

In a recent paper, Grainger and Jacobs (1996) claimed that participants have control over the type of information they use to generate a response in the lexical decision 
task. These authors proposed that a positive lexical decision response can be triggered on the basis of (1) unit activity of whole-word representations or (2) the summed activity of all word units (i.e., global lexical activity). Grainger and Jacobs refer to the response criterion set on unit activity as the $M$ criterion and refer to the criterion set on summed activity as $\sum$ (note that their analysis was limited to orthographic information as implemented in the original interactive activation model of McClelland \& Rumelhart, 1981). Here, we distinguish between a criterion set on unit activity in an orthographic lexicon $(\mathrm{O}-\mathrm{M})$ and a criterion set on unit activity in a phonological lexicon (P-M) in a bimodal interactive activation model (see Grainger \& Ferrand, 1994; Ziegler \& Jacobs, 1995). In this case, summed lexical activity refers to the total activity in both orthographic and phonological word units.

It is hypothesized that the type of nonword used in a lexical decision task will affect the degree to which the phonological $\mathrm{M}$ criterion (P-M) and the $\Sigma$ criterion can be used in generating a positive lexical decision response. More specifically, it is hypothesized that the presence of pseudohomophone foils (e.g., BEEST) will force participants to abandon use of the $\mathrm{P}-\mathrm{M}$ criterion, since this will provoke too many false positive responses to such stimuli. Furthermore, since pseudohomophones generate higher levels of global lexical activity than do nonhomophonic nonwords (due to the extra activity in the phonological lexicon), their presence will discourage use of the $\sum$ criterion. On the other hand, the presence of orthographically illegal nonwords (e.g., TSDEE) should encourage participants to use the $\sum$ criterion, since such nonwords can be easily discriminated from words on the basis of summed lexical activity. In the model, the decreased use of the $\Sigma$ criterion explains the typical increase in RT and error rate to word stimuli that occur with increases in nonword foil lexicality (e.g., Stone \& Van Orden, 1993).

Two points are critical with respect to our predictions concerning variations in pseudohomophone and homophone priming effects as a function of nonword context. First, both pseudohomophone and homophone primes are phonologically identical to their corresponding targets. They differ in terms of their lexical status and, therefore, in terms of the amount of lexical inhibition they generate (i.e., mutual inhibition among word units in an interactive activation model). In the present theoretical framework, inhibitory effects between whole-word orthographic representations are maximal with high-frequency orthographically related word primes (the homophone primes in the present experiment). Pseudohomophone primes also generate some orthographic inhibition (to the extent that they activate whole-word orthographic units other than the target word), but this will be considered negligible for the present purposes. Second, facilitatory effects of phonological priming are hypothesized to be strongest with readout from the $\mathrm{P}-\mathrm{M}$ criterion. Inhibitory effects of orthographic priming are hypothesized to be strongest with readout from the $\mathrm{O}-\mathrm{M}$ criterion. ${ }^{2}$
Table 1 summarizes the qualitative predictions of the bimodal multiple readout model. Both pseudohomophone and homophone primes generate the same level of phonological facilitation, and this ought to be maximal with readout from the $\mathrm{P}-\mathrm{M}$ criterion. On the other hand, effects of orthographic inhibition are considered negligible with pseudohomophone primes and maximal with homophone primes when readout is from the $\mathrm{O}-\mathrm{M}$ criterion. Summing the positive and negative effects of homophone primes, the model predicts a null effect of homophone priming with illegal nonwords, a facilitatory effect with legal nonwords, and an inhibitory effect with pseudohomophone primes. The results of Grainger and Ferrand (1994) provide support for the last two predictions. However, as noted above, the pattern of effects obtained by Grainger and Ferrand might be the result of the type of target word tested (homophone or not). The present experiment used the same set of target words (all homophones) in the different priming conditions.

\section{METHOD}

\section{Participants}

Seventy-two psychology students at René Descartes University, Paris, took part in the experiment for course credit. The participants were randomly assigned to one of three groups (legal nonword, pseudohomophone, and illegal nonword). All were native speakers of French, with normal or corrected-to-normal vision.

\section{Stimuli and Design}

Thirty four- to five-letter French heterographic homophone mates with contrasting frequencies were selected (e.g., FOls-FolE). The lowfrequency member served as target word (average frequency of $25 \mathrm{oc}-$ currences per million; Trésor de la Langue Française, 1971). Three types of prime were selected for each target: (1) the high-frequency homophone mate (average frequency of 467 occurrences per million), (2) nonword primes that were homophonic with and orthographically related to the target (e.g., foit-FOIE), and (3) word primes (matched in frequency to Category 1) that were unrelated to the target (e.g., avec-FOIE). Each prime had the same length as the corresponding target, and none of the prime-target pairs were semantically related in any transparent way. Prime-target pairs were rotated across the priming conditions across different participants such that no participant saw any single prime or target more than once, but each participant received all three priming conditions. Three sets of 30 nonword foils were generated, one for each of the nonword lexicality conditions. One group of participants received only pronounceable (nonhomophonic) legal non-

Table 1

Predicted Phonological Facilitation $(\mathrm{P}+)$ and Orthographic Inhibition ( $\mathrm{O}^{-}$) Generated by Primes That Are Either Pseudohomophones or Homophones of Word Targets in a Lexical Decision Task in the Presence of Illegal, Legal, or Pseudohomophone Foils

\begin{tabular}{lccc}
\hline & \multicolumn{3}{c}{ Type of Nonword } \\
\cline { 2 - 4 } Type of Prime & $(\Sigma)$ & $\begin{array}{c}\text { Legal } \\
(\mathrm{P}-\mathrm{M})\end{array}$ & $\begin{array}{c}\text { Pseudohomophone } \\
(\mathrm{O}-\mathrm{M})\end{array}$ \\
\hline Pseudohomophone & $\mathrm{P}+$ & $\mathrm{P}++$ & $\mathrm{P}+$ \\
Homophone & $\mathrm{P}+$ & $\mathrm{P}++$ & $\mathrm{P}+$ \\
& $\mathrm{O}-$ & $\mathrm{O}-$ & $\mathrm{O}--$
\end{tabular}

Note--In parentheses are the information dimensions that are hypothesized to generate optimal performance with each type of nonword (for the priming conditions tested in the present experiment). The number of plus $(+)$ or minus $(-)$ signs indicates the predicted size of the effect. 
word targets. The stimulus list for the second group of participants was created by replacing $33 \%$ of the legal nonwords in the first list with pseudohomophones. Each pseudohomophone target differed from its base word by a single letter, and the average base-word frequency was 320 occurrences per million (Trésor de la Langue Française, 1971). Pseudohomophone status was evaluated using the procedure of Stone and Van Orden (1993). Finally, the third group of participants received illegal nonword targets constructed by permuting the letters of the legal nonwords, so that the resulting letter strings violated French orthography and were difficult to pronounce. Each of the three groups received the same set of word targets. Priming condition (within participants) was crossed with type of nonword (between participants) in a $3 \times 3$ design. All nonword targets were four to five letters long and were preceded by three types of prime. For the legal nonword group and the pseudohomophone group, one third of the nonword targets were primed by a nonword that was homophonic with and orthographically related to the target (e.g., nart-NARE), one third were preceded by orthographically related nonhomophonic nonword primes (e.g., fape-FIPE), and one third were preceded by unrelated nonword primes (e.g., prue-CLON). For the illegal nonword targets, primes were identical (e.g., rnae-RNAE), orthographically related (e.g., rfae-RNAE), or unrelated (e.g., dsta-RNAE).

\section{Procedure}

Stimuli were presented in isolation on the center of the display screen of a personal computer with a $70-\mathrm{Hz}$ refresh rate. The items appeared on the screen as white characters on dark background. Each character (in uppercase) covered approximately $0.38^{\circ}$ of visual angle from a viewing distance of $60 \mathrm{~cm}$. Thus, a four-letter word subtended about $1.53^{\circ}$ of visual angle. The masked prime procedure with the lexical decision task used in the experiments of Segui and Grainger (1990) was adopted here. Each trial consisted of the following sequence of three stimuli First, a forward mask consisting of a row of four or five hash marks (depending on the length of the prime/target) was presented for $500 \mathrm{msec}$, followed immediately by the prime stimulus in lowercase letters for $57 \mathrm{msec}$, followed immediately by the target stimulus in uppercase letters, both presented in the same screen location as the mask. The target remained on the screen until the participants responded. Primes were always presented in lowercase and targets in uppercase in order to minimize physical overlap with orthographically related pairs. The participants were instructed to respond as rapidly and as accurately as possible whether or not the letter string in uppercase that remained on the screen was a French word. The existence of a prime stimulus was not mentioned. The participants responded "yes" by pressing one of the two response buttons with the forefinger of the preferred hand and "no" by pressing the other response button with the forefinger of the nonpreferred hand. The next sequence followed after a 1-sec delay. Reaction times (RTs), measured from target onset until the participants' response, were accurate to the nearest millisecond. Stimulus presentation was randomized, with a different order for each participant.

\section{RESULTS}

Mean correct positive lexical decision latencies and percentage of errors are given in Table 2 for the different experimental conditions. The raw data were log-transformed before statistical analysis, and no cutoffs were applied. ${ }^{3}$ An analysis of variance (ANOVA) was performed, with priming condition (homophone, pseudohomophone, or unrelated) and type of nonword (illegal, legal, or pseudohomophone) entered as main factors. $F$ values are reported by participant $(F 1)$ and by item $(F 2)$.

In the ANOVA performed on RTs, there were significant main effects of priming condition $[F 1(2,42)=51.89$, $p<.001 ; F 2(2,174)=27.53, p<.001]$ and type of nonword $[F 1(2,42)=82.31, p<.001 ; F 2(2,87)=519.03$, $p<.001]$ and a significant interaction between these two factors $[F 1(4,84)=28.38, p<.001 ; F 2(4,174)=5.63$, $p<.01]$. Planned comparisons indicate that, relative to unrelated primes, homophone primes did not significantly affect RTs in the illegal nonword context $[F 1(1,21)<1$; $F 2(1,29)=1.36$ ] but produced faster RTs in the legal nonword context $[F 1(1,21)=27.29, p<.01 ; F 2(1,29)=$ $8.92, p<.01]$ and slower RTs in the pseudohomophone nonword context $[F 1(1,21)=20.19, p<.001 ; F 2(1,29)=$ $15.04, p<.005]$. Relative to unrelated primes, pseudo-

Table 2

Mean Lexical Decision Latencies ( $M$, in Milliseconds) and Percentage of Errors (\% Errors) to Word Targets Preceded by Orthographically Related Homophone, Orthographically Related Pseudohomophone, and Unrelated Primes in the Three Nonword Lexicality Conditions

\begin{tabular}{|c|c|c|c|c|c|c|}
\hline & \multicolumn{6}{|c|}{ Nonword Lexicality } \\
\hline & \multicolumn{2}{|c|}{ Illegal } & \multicolumn{2}{|c|}{ Legal } & \multicolumn{2}{|c|}{ Pseudohomophone } \\
\hline & $M$ & $\%$ Error & $M$ & $\%$ Error & $M$ & $\%$ Error \\
\hline \multicolumn{7}{|c|}{ Word Trials } \\
\hline $\begin{array}{l}\text { Priming Condition } \\
\text { Pseudohomophonic and } \\
\text { orthographically similar } \\
\text { prime (e.g., foit-FOIE) }\end{array}$ & 433 & 2.5 & 567 & 8.0 & 701 & 10.1 \\
\hline $\begin{array}{l}\text { Homophonic and } \\
\text { orthographically similar } \\
\text { prime (e.g., fois--FOIE) }\end{array}$ & 466 & 4.5 & 565 & 8.4 & 799 & 14.6 \\
\hline $\begin{array}{l}\text { Unrelated prime } \\
\text { (e.g., avec-FOIE) }\end{array}$ & 469 & 5.4 & 606 & 10.6 & 751 & 12.2 \\
\hline \multicolumn{7}{|l|}{ Priming Effect } \\
\hline Pseudohomophone & +36 & +2.9 & +39 & +2.6 & +50 & +2.1 \\
\hline Homophone & +3 & +0.9 & +41 & +2.2 & -48 & -2.4 \\
\hline \multicolumn{7}{|c|}{ Nonword Trials } \\
\hline & 529 & 3.2 & 651 & 8.5 & 814 & 13.5 \\
\hline
\end{tabular}

Note-The same set of target words were tested in the three nonword lexicality conditions. 
homophone primes produced faster RTs in the illegal nonword context $[F 1(1,21)=34.93, p<.001 ; F 2(1,29)=$ $98.95, p<.001]$, in the legal nonword context $[F 1(1,21)$ $=50.41, p<.001 ; F 2(1,29)=8.51, p<.01]$, and in the pseudohomophone context $[F 1(1,21)=37.71, p<.001$; $F 2(1,29)=10.13, p<.005]$.

The results of an ANOVA performed on the percent errors to word targets mirrored the pattern obtained in the RT analysis. There were significant main effects of priming condition $[F 1(2,42)=11.31, p<.001 ; F 2(2,174)=$ $3.12, p<.05]$ and of type of nonword $[F 1(2,42)=27.42$, $p<.001 ; F 2(2,87)=5.03, p<.01]$ and a significant priming condition $\times$ type of nonword interaction $[F 1(4,84)=$ $4.81, p<.005 ; F 2(4,174)=2.89, p<.05]$. Planned comparisons against the unrelated prime condition gave an almost identical pattern of effects as the RT analysis. The only difference was that pseudohomophone primes did not significantly affect error rate in the pseudohomophone nonword context $[F 1(1,21)<1 ; F 2(1,29)=1.65]$.

\section{DISCUSSION}

The results of the present experiment can be summarized as follows: When primes are pseudohomophones of low-frequency target words, facilitatory effects are obtained, relative to unrelated controls. These effects are independent of the type of nonword inserted as foils in the experimental lists. On the other hand, when primes are high-frequency homophones of the target, very different priming effects are obtained as a function of the type of nonword foil: Facilitatory effects are obtained in the presence of orthographically legal pronounceable nonwords, inhibitory effects are obtained when the nonwords include pseudohomophones, and null effects are obtained when illegal nonwords are present.

The present results show a clear dissociation in the effects of nonword foils on masked phonological priming with pseudohomophone and homophone primes, thus confirming our prior work (Ferrand \& Grainger, 1992; Grainger \& Ferrand, 1994). This dissociation was obtained using the same set of target words (all homophones), thus allowing us to reject an interpretation of the absence of nonword context effects on pseudohomophone priming in our 1992 experiment in terms of the lower percentage of homophone targets used. It appears that the lexical status of the phonologically related prime determines the pattern of priming effects obtained as a function of nonword context in the lexical decision task.

\section{LIST CONTEXT EFFECTS ON PHONOLOGICAL PRIMING}

List context effects in lexical decision have generally been taken as evidence that participants have some form of strategic control over the way they perform this task. This strategic control can be expressed in terms of pathway selection processes in boxology models. Thus, for example, in order to account for their observation that phonological inconsistency effects disappear when pseudohomophones are added to the experimental lists, Pugh, Rexer, and Katz (1994) concluded that the assembled phonology route is disabled in the presence of pseudohomophone foils in the lexical decision task. This position cannot account for the pseudohomophone priming effects obtained in the presence of pseudohomophone foils in the present experiment, since pseudohomophone priming effects must necessarily arise via assembled phonology.
Alternatively, it may be hypothesized that strategic control reflects adjustments of task-specific response criteria. The critical difference with respect to pathway selection models is that strategic control does not affect the type of information computed during visual word recognition, but rather it affects what is done with information that is automatically computed. Thus, it was hypothesized that three different criteria for a positive lexical decision response were operational in the present experiment: one criterion set on unit activity in an orthographic lexicon $(\mathrm{O}-\mathrm{M})$, one set on unit activity in a phonological lexicon $(\mathrm{P}-\mathrm{M})$, and one set on total lexical activity in both lexica $(\Sigma)$. Table 1 summarizes the predictions generated from this theoretical framework, which we tested in the present experiment. All of the main predictions were supported by the experimental data.

Another example of list composition effects on masked phonological priming has been provided by Verstaen, Humphreys, Olson, and d'Y dewalle (1995). These authors observed that, when only homophone targets were used in Perfetti et al.'s (1988) backward masking paradigm, orthographic but not phonological priming effects were obtained. With nonhomophones inserted among the targets, the phonological priming effect reappeared (for both the homophone and nonhomophone targets). The authors suggested that homophone targets encourage subjects to use a visual (orthographic) rather than a phonological identification strategy, since a phonological representation does not discriminate between the two spellings of a homophone target (necessary for a correct perceptual identification response). In the present theoretical framework, this implies increased readout from the orthographic lexicon (O-M criterion) with homophone targets. The fact that phonological priming occurs with homophone targets when participants first receive nonhomophones in the experimental list (i.e., are encouraged to use the $\mathrm{P}-\mathrm{M}$ criterion) suggests that readout from the phonological lexicon can lead to successful homophone identification. Letterlevel information could be used to complete the ambiguous orthographic information made available upon identification of a phonological form.

In conclusion, the present study suggests that phonological information is always generated from a pronounceable string of letters, independent of list context. List context influences the criteria that participants adopt for responding in the lexical decision task. Priming effects will depend on whether these response criteria are sensitive to the informational overlap between prime and target.

\section{REFERENCES}

Ferrand, L., \& Grainger, J. (1992). Phonology and orthography in visual word recognition: Evidence from masked nonword priming. Quarterly Journal of Experimental Psychology, 42A, 353-372.

Grainger, J., \& Ferrand, L. (1994). Phonology and orthography in visual word recognition: Effects of masked homophone primes. Journal of Memory \& Language, 33, 218-233.

GraingER, J., \& JACOBS, A. M. (1996). Orthographic processing in visual word recognition: A multiple read-out model. Psychological Review, 103, 518-565. 
Humphreys, G. W., Evett, L. J., \& Taylor, D. E. (1982). Automatic phonological priming in visual word recognition. Memory \& Cognition, 10, 576-590.

JaCOBS, A. M., Grainger, J., \& Ferrand, L. (1995). The incremental priming technique: A method for determining within-condition priming effects. Perception \& Psychophysics, 57, 1101-1110.

LuKaTEla, G., \& TuRvey, M. T. (1994). Visual lexical access is initially phonological: 2. Evidence from phonological priming by homophones and pseudohomophones. Journal of Experimental Psychology: General, 123, 331-353.

MCClelland, J. L., \& Rumelhart, D. E. (1981). An interactive activation model of context effects in letter perception: Part l. An account of basic findings. Psychological Review, 88, 375-407.

Perfetti, C. A., Bell, L. C., \& Delaney, S. M. (1988). Automatic (prelexical) phonetic activation in silent word reading: Evidence from backward masking. Journal of Memory \& Language, 27, 59-70.

Pugh, K. R., ReXer, K., \& KaTZ, L. (1994). Evidence of flexible coding in visual word recognition. Journal of Experimental Psychology: Human Perception \& Performance, 20, 807-825.

RATCLIFF, R. (1993). Methods for dealing with reaction time outliers. Psychological Bulletin, 114, 510-532.

Segui, J., \& Grainger, J. (1990). Priming word recognition with orthographic neighbors: Effects of relative prime-target frequency. Journal of Experimental Psychology: Human Perception \& Performance, 16, 65-76.

Stone, G. O., \& Van ORden, G. C. (1993). Strategic control of processing in word recognition. Journal of Experimental Psychology: Human Perception \& Performance, 19, 744-774.

Trésor de la Langue Française [French language frequency counts]
(1971). Nancy, France: Centre National de la Recherche Scientifique. Verstaen, A., Humphreys, G., Olson, A., \& D'Yoewalle, G. (1995). Are phonemic effects in backward masking evidence for automatic prelexical phonemic activation in visual word recognition? Journal of Memory \& Language, 34, 335-356.

ZIEGLER, J. C., \& JACOBS, A. M. (1995). Phonological information provides early sources of constraint in the processing of letter strings. Journal of Memory \& Language, 34, 567-593.

\section{NOTES}

1. This study also replicated the inhibitory effects of high-frequency orthographically related (nonhomophone) primes on lexical decision responses to low-frequency word targets first reported by Segui and Grainger (1990). Segui and Grainger showed that these priming effects disappeared when the prime-target frequency relationship was reversed. It is this result that motivates the choice of high-frequency primes and low-frequency targets in the present experiment.

2 . The terms inhibition and facilitation are used here to refer to increases and decreases in RT and/or percent errors relative to an unrelated prime condition. However, see Jacobs, Grainger, and Ferrand (1995) for a discussion of alternative ways of interpreting these concepts.

3. Applying either a $1,000-\mathrm{msec}$ or a $1,500-\mathrm{msec}$ cutoff without $\log$ transform changed neither the pattern of means nor the significance of effects (Ratcliff, 1993).

(Manuscript received August 24, 1995; revision accepted for publication July 2, 1996.) 